\title{
Establishment of an efficient transformation protocol and its application in marine-derived Bacillus strain
}

\author{
LIU Yang ${ }^{1}$, ZHENG Hua $^{1}$, ZHAN GuiHua $^{1}$, QIN Wen $^{1}$, TIAN Li $^{2,3} \&$ LI WenLi $^{1 *}$ \\ ${ }^{1}$ Key Laboratory of Marine Drugs, Ministry of Education of China, School of Medicine and Pharmacy, Ocean University of China, Qingdao \\ 266003, China; \\ ${ }^{2}$ First Institute of Oceanography, State Oceanic Administration, Qingdao 266061, China; \\ ${ }^{3}$ Qingdao University of Science \& Technology, Qingdao 266042, China
}

Received October 31, 2013; accepted December 7, 2013; published online April 24, 2014

\begin{abstract}
Marine-derived Bacillus strains have been proved to be a very promising source for natural product leads. However, transformation of environmental strains is much more difficult than that of domesticated strains. Here, we report the development of an efficient and robust electroporation-based transformation system for marine-derived Bacillus marinus B-9987, which is a macrolactin antibiotics producer and a very promising biological control agent against fungal plant diseases. The transformation efficiency was greatly enhanced $10^{3}$-fold by using unmethylated plasmid to bypass modification-restriction barrier, and using glycine betaine to protect cells from electrical damages during electroporation. Addition of HEPES and $2 \mathrm{mmol} \mathrm{L}^{-1}$ $\mathrm{MgCl}_{2}$ further improved the efficiency by additional 2-fold, with a maximum value of $7.1 \times 10^{4} \mathrm{cfu} / \mu \mathrm{g}$ pHT3101. To demonstrate the feasibility and efficiency of the protocol, a green fluorescent protein reporter system was constructed; furthermore, phosphopantetheinyl transferase gene $s f p$, which is essential to the biosynthesis of polyketides and nonribosomal peptides, was overexpressed in B-9987, leading to increased production of macrolactin A by about 1.6-fold. In addition, this protocol is also applicable to marine-derived Bacillus licheniforms EI-34-6, indicating it could be a reference for other undomesticated Bacillus strains. To our knowledge, this is the first report regarding the transformation of marine-derived Bacillus strain.
\end{abstract}

marine-derived, Bacillus marinus, electroporation, macrolactin, green fluorescent protein, phosphopantetheinyl transferase

Citation: $\quad$ Liu Y, Zheng H, Zhan GH, Qin W, Tian L, Li WL. Establishment of an efficient transformation protocol and its application in marine-derived Bacillus strain. Sci China Life Sci, 2014, 57: 627-635, doi: 10.1007/s11427-014-4632-3

With the exploitation of marine bio-resources for bioactive compounds, an increasing number of Bacillus strains were identified to produce potentially significant secondary metabolites [1]. However, no in vivo studies of these strains have been reported so far in the absence of genetic manipulation system, which has hindered the understanding of their metabolic machinery on the molecular level. Bacillus marinus B-9987 was isolated from the rhizosphere of Suaeda salsa collected in the intertidal zone of Bohai Bay of Eastern China [2]. Chemical investigations revealed that

*Corresponding author (email: liwenli@ouc.edu.cn)
B. marinus B-9987 is capable to produce a variety of antimicrobial secondary metabolites [3-5], such as macrolactins (Figure 1), which are able to inhibit the growth of plant fungal pathogens Pyricularia oryzae and Alternaria solani by destroying their cell walls [5]. Besides antifungal activity, macrolactins also exhibit antibacterial, antiviral, anticancer, anti-inflammatory, and as well as antiangiogenic activities [6-9]. Macrolactin A was proposed to be assembled by trans-acyltransferase polyketide synthases (trans-AT PKSs) [10], which require the phosphopantetheinyl transferase (PPTase) to convert acyl carrier proteins (ACPs) from apo- 


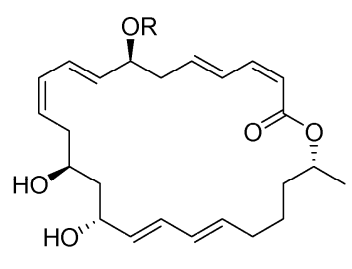

Macrolactin $\mathrm{A}, \mathrm{R}=\mathrm{H}$

Macrolactin $B, R=\beta$-glucose

Macrolactin D, $R=6$-O-succinyl- $\beta$-glucose

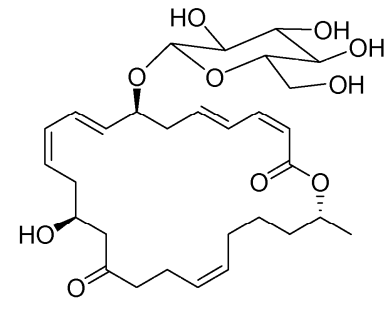

Macrolactin O

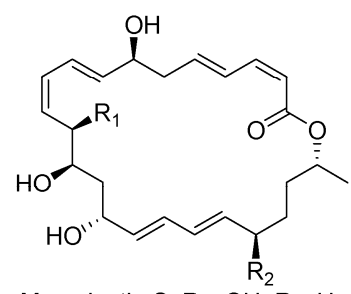

Macrolactin S, $\mathrm{R}_{1}=\mathrm{OH}, \mathrm{R}_{2}=\mathrm{H}$ Macrolactin $\mathrm{T}, \mathrm{R}_{1}=\mathrm{H}, \mathrm{R}_{2}=\mathrm{OH}$

Figure 1 Structures of macrolactins isolated from the fermentation broth of B. marinus B-9987.

forms (inactive) into holo-forms (active) [11]. Field trails proved that B. marinus B-9987 is a very promising biological control agent against fungal plant diseases [12], but the molecular mechanism of its biocontrol ability is still unknown due to the lack of genetic manipulation system. Therefore, it is valuable and necessary to develop a sound and convenient transformation strategy in B. marinus B-9987, which will lay the foundation for functional genomics research and further strain improvement by genetic engineering, and more importantly, would be a reference for other environmental Bacillus strains.

Several strategies have been reported for transformation of Bacillus, including natural competence, electroporation, protoplast fusion, and protoplast electroporation, among which electroporation is the most universal and convenient technique [13]. A variety of electroporation protocols have been developed and optimized with many factors, such as cell wall weakening agents, electroporation buffers and pulse voltage, plasmids with various replicons, and culture conditions [14-16]. However, most of these protocols were developed by using reference or domesticated strains and are not always effective for naturally isolated Bacillus strains [17-19]. Thus, it has been very challenging to develop transformation protocol for environmental Bacillus strains. To transform the marine-derived B. marinus B-9987, several strategies including natural competence, protoplast fusion, and protoplast electroporation had been initially attempted, but barely any transformant was obtained.

Herein, for the first time we developed an efficient electroporation-based transformation strategy for marine-derived Bacillus strain by focusing on three critical issues: cell restriction activity, sporulation rate and survival rate. The influence of growth condition, composition of transformation medium, and electric fields on the transformation efficiency was evaluated. By applying the established transformation protocol, a green fluorescent protein (GFP) gene was introduced into B. marinus B-9987 and was expressed successfully, which could be used as a sensitive reporter. Furthermore, in view of the antifungal activity of macrolactins and their manner of biosynthesis, the PPTases gene $s f p$ was overexpressed in B. marinus B-9987, resulting in increased macrolactin A production. This demonstrated the feasibility of genetic manipulation in B. marinus B-9987 by using the established approach, which will promote understanding of the molecular mechanism of biocontrol by $B$. marinus B-9987, and subsequent strain improvement via metabolic engineering.

\section{Materials and methods}

\subsection{Strains and plasmids}

Bacterial strains and plasmids used and constructed during this study are listed in Table S1 in Supporting Information. Escherichia coli $\mathrm{DH} 5 \alpha$ was used for general cloning. The dam, dcm, and hsdRMS-deficient Escherichia coli ET12567 [20] was used to prepare the unmethylated E. coli-Bacillus shuttle plasmids. The B. marinus B-9987 (CGMCC No. 2095) [2] and Bacillus licheniforms strain EI-34-6 (BGSC catalog 5A37) [21] have been described previously. The replicative plasmids with different replicons and antibiotic resistance markers, including pHT3101 [22], pKSV7 [23] and pIKM1 [24], were used for method development and evaluation. Plasmids extractions and DNA purifications were carried out using commercial kits (Omega Bio-Tek, USA).

\subsection{Media, chemicals, and culture conditions}

E. coli strains and Bacillus strains were routinely cultured in Luria-Bertani (LB) liquid medium at $37^{\circ} \mathrm{C}, 200 \mathrm{r} \mathrm{min}^{-1}$, or $\mathrm{LB}$ agar plate at $37^{\circ} \mathrm{C}$. When appropriate, ampicillin (Amp; $100 \mu \mathrm{g} \mathrm{mL}^{-1}$ for E. coli), chloramphenicol (Chl; $5 \mu \mathrm{g} \mathrm{mL}^{-1}$ for Bacillus), kanamycin (Kan; $100 \mu \mathrm{g} \mathrm{mL}^{-1}$ for E. coli and $50 \mu \mathrm{g} \mathrm{mL}^{-1}$ for Bacillus), and erythromycin (Erm; $5 \mu \mathrm{g}$ $\mathrm{mL}^{-1}$ for Bacillus) was added to the medium. The B. marinus B-9987 transformants harboring plasmid pKSV7 were incubated at $30^{\circ} \mathrm{C}$.

In initial screening of the optimal medium for electro-competent cell preparation, B. marinus B-9987 was grown in various media, including LB, LBS (LB containing $0.5 \mathrm{~mol} \mathrm{~L}^{-1}$ sorbitol), LBSG (LB containing $0.5 \mathrm{~mol} \mathrm{~L}^{-1}$ 
sorbitol and $7.5 \%$ glycine betaine) [25], and neutral complex medium (NCM) [26] (17.4 g K $\mathrm{gPO}_{2}, 11.6 \mathrm{~g} \mathrm{NaCl}, 5$ $\mathrm{g}$ glucose, $5 \mathrm{~g}$ tryptone (Oxoid, UK), $1 \mathrm{~g}$ yeast extract (Oxoid), $0.3 \mathrm{~g}$ trisodium citrate, $0.05 \mathrm{~g} \mathrm{MgSO}_{4} \cdot 7 \mathrm{H}_{2} \mathrm{O}$, and 91.1 $\mathrm{g}$ sorbitol in $1 \mathrm{~L}$ deionized water, $\mathrm{pH}$ 7.2).

\subsection{Preparation of the electro-competent cells}

For preparation of the electro-competent cells, an overnight culture $(5 \mathrm{~mL}$ ) of $B$. marinus B-9987 cells using different media was transferred to each corresponding fresh medium $(50 \mathrm{~mL})$ at a 10 -fold dilution, and incubated at $37^{\circ} \mathrm{C}, 200 \mathrm{r}$ $\min ^{-1}$. The growth was monitored by measuring the optical density $(A)$ at $600 \mathrm{~nm}$. When an $A_{600}$ reading reached $0.90-0.95$, the cell culture was cooled on ice for $5 \mathrm{~min}$, and collected by centrifugation at $4^{\circ} \mathrm{C}, 5000 \times g$ for $5 \mathrm{~min}$. After washing three times with different ice-cold electroporation media, the electro-competent cells were resuspended in $1 / 100$ volume of the original culture, and were used directly or stored at $-80^{\circ} \mathrm{C}$ for future use.

Electroporation media tested in this study included the conventional electroporation medium (CEM) $\left(0.5 \mathrm{~mol} \mathrm{~L}{ }^{-1}\right.$ sorbitol, $0.5 \mathrm{~mol} \mathrm{~L}^{-1}$ mannitol and $10 \%$ glycerol) [27], CEM supplemented with $2.5 \%-10 \%$ glycine betaine (GLYB) [25], CEM supplemented with $7.5 \%$ GLYB and 1 mmol $\mathrm{L}^{-1}$ HEPES, and CEM supplemented with $7.5 \%$ GLYB, $1 \mathrm{mmol} \mathrm{L}{ }^{-1} \mathrm{HEPES}$, and $1-10 \mathrm{mmol} \mathrm{L}^{-1} \mathrm{MgCl}_{2}$.

\subsection{Electroporations}

Electro-competent cells $(60 \mu \mathrm{L})$ were mixed with $100 \mathrm{ng}$ of plasmid DNA (unmethylated unless otherwise specified), and loaded into a prechilled 1-mm gap electroporation cuvette. After 5 min of incubation on ice, the cell-DNA mixture was shocked by a single $18 \mathrm{kV} \mathrm{cm}^{-1}$ pulse generated by Bio-Rad Gene Pulser apparatus (Bio-Rad laboratories, USA). $1 \mathrm{~mL}$ of recovery medium (LB containing $0.5 \mathrm{~mol} \mathrm{~L}^{-1}$ sorbitol, $0.38 \mathrm{~mol} \mathrm{~L}^{-1}$ mannitol, and $10 \%$ glycerol) was added to the cells right after the pulse delivery. The cells were shaken gently at $37^{\circ} \mathrm{C}$ for $3 \mathrm{~h}$ to allow expression of the antibiotic resistance genes. Aliquots were then spread onto LB agar plates supplemented with appropriate antibiotics. Transformants were verified by plasmid extraction and restriction enzyme digestion. Transformation efficiencies were calculated by counting the colonies on plates after incubation at $37^{\circ} \mathrm{C}$ overnight (pHT3101 and pIKM1) or at $30^{\circ} \mathrm{C}$ for $24 \mathrm{~h}$ (pKSV7).

\subsection{Plasmid construction}

p3101GFP, which harbors a green fluorescent protein (GFP) gene $g f p$ under the control of the promoter of glyceraldehyde-3-phosphate dehydrogenase gene gapDH (gapDHp), was constructed as follows: the gapDHp promoter was am- plified from the genome of B. marinus B-9987 by using primer pair of gapDHp-FP/gapDHp-RP: 5'-GGAATTCTGGAATACGAGCTGAGTG-3' (EcoR I site underlined)/5ACGCGTCGACCATTCTTCCGATTCTAC-3' (Sal I site underlined); the $g f p$ gene was amplified from plasmid pHL015 [28] by using primer pair of gfp-FP/gfp-RP: 5'-ACGCGTCGACATGTCGAAGGGCGAGGAGC-3 (Sal I site underlined)/5'-GCTCTAGATTATCCTTACTACTTG3' (Xba I site underlined); the above DNA fragments were cloned into the EcoR I and Xba I sites of pHT3101 to yield p3101GFP. p3101GFP isolated from E. coli ET12567 was introduced into B. marinus B-9987.

To overexpress the phosphopantetheinyl transferase, the gene $s f p$ was amplified from the genome of $B$. marinus B-9987 by using primer pair of sfp-FP/sfp-RP: 5'ACGCGTCGACATGAAGATTTACGGAGTATA-3' (Sal I site underlined)/5'-GCTCTAGATTATAACAGCTCTTCATACG (Xba I site underlined). After digestion with Sal I and $X b a$ I, the amplified DNA was cloned into the same sites of p3101GFP to replace the $g f p$ gene with the $s f p$ gene, generating $\mathrm{p} 3101 \mathrm{SFP}$. The nucleotide sequence of the $s f p$ gene has been deposited in the GenBank database under accession number KF672549. p3101SFP isolated from $E$. coli ET12567 was introduced into B. marinus B-9987.

\subsection{Fluorescent microscopy}

Transformants carrying p3101GFP and pHT3101 were grown in LB medium supplemented with $5 \mu \mathrm{g} \mathrm{mL}^{-1}$ of erythromycin at $37^{\circ} \mathrm{C}$ overnight, respectively. In vivo fluorescence imaging of the cells was examined under an inverted fluorescence microscope (DMI 6000 B; Leica Microsystems, Germany) using a mercury vapor lamp with blue excitation $\left(\lambda_{\mathrm{ex}}=488 \mathrm{~nm}\right)$.

\subsection{Fermentation and HPLC analysis}

B. marinus B-9987 wild-type and overexpression strains were fermented in Landy medium [29] using a two-stage fermentation process: a single colony of the B. marinus B-9987 strains was first inoculated into $50 \mathrm{~mL}$ of seed medium in a $250-\mathrm{mL}$ flask and incubated at $37^{\circ} \mathrm{C}, 200 \mathrm{r} \mathrm{min}^{-1}$ for $12 \mathrm{~h}$. The resulting seed culture $(5 \mathrm{~mL})$ was used to inoculate $50 \mathrm{~mL}$ of production medium in a $250-\mathrm{mL}$ flask and incubated at $37^{\circ} \mathrm{C}, 200 \mathrm{r} \mathrm{min}^{-1}$ for additional $12 \mathrm{~h}$. The fermentation broth was centrifuged at $5000 \times \mathrm{g}$ for $10 \mathrm{~min}$ to remove the cells. The resulting supernatant was extracted twice with equal volume of EtOAc. The combined EtOAc extracts were concentrated in vacuo to afford an oily residue. The latter was dissolved in $\mathrm{MeOH}$, filtered through a $0.2-\mu \mathrm{m}$ filter, and subjected to HPLC analysis. The HPLC system consisted of Agilent 1260 Infinity Quaternary pumps and a 1260 Infinity diode-array detector. Analytical HPLC was performed on a YMC-Pack ODS-AQ C18 column $(5 \mu \mathrm{m}, 4.6 \mathrm{~mm} \times 150 \mathrm{~mm})$ developed with a linear gra- 
dient from $38 \%$ to $53 \% \mathrm{ACN} / \mathrm{H}_{2} \mathrm{O}$ in $10 \mathrm{~min}$, followed by an additional $10 \mathrm{~min}$ at $100 \% \mathrm{ACN}$ at a flow rate of $1 \mathrm{~mL}$ $\min ^{-1}$ and UV detection at $260 \mathrm{~nm}$. The identity of macrolactin A was determined by comparison of retention time and UV spectrum with the standard, and was further confirmed by MS analysis. Liquid chromatography-MS was carried out on an Agilent 1260 HPLC-MSD SL quadrupole mass spectrometer equipped with both orthogonal pneumatically assisted electrospray and atmospheric pressure chemical ionization sources (Santa Clara, USA).

\subsection{Electroporation of marine-derived $B$. licheniforms strain EI-34-6}

An overnight culture of $B$. licheniforms strain EI-34-6 cells was transferred to NCM growth medium at a 10-fold dilution, and incubated at $37^{\circ} \mathrm{C}, 200 \mathrm{r} \mathrm{min}^{-1}$, until an $A_{600}$ reading reached $0.90-0.95$. The cells were washed using three different ice-cold electroporation media, including CEM, CEM supplemented with 7.5\% GLYB, and CEM supplemented with $7.5 \%$ GLYB, $1 \mathrm{mmol} \mathrm{L}^{-1}$ HEPES and $2 \mathrm{mmol}$ $\mathrm{L}^{-1} \mathrm{MgCl}_{2}$. A single $20 \mathrm{kV} \mathrm{cm}$ pulse was used for electroporation.

\section{Results}

\subsection{Effects of restriction system and culture conditions on transformation efficiency}

Since the restriction-modification (R-M) systems function as barriers against invasion of foreign DNA, which are commonly related to low transformation efficiencies [30], methylated and unmethylated E. coli-Bacillus shuttle vector pHT3101, which was extracted from $E$. coli DH5 $\alpha$ and $E$. coli ET12567, respectively, were tested to transform B-9987. As the endospores of Bacillus endowed the cell a firm coat and are hardly accessible by exogenous DNA $[31,32]$, the growth culture condition was studied to obtain cells with decreased sporulation rate and relatively weak cell wall. Media with different nutritional ingredients and osmotic agents were tested, including LB, LBS (LB containing $0.5 \mathrm{~mol} \mathrm{~L}^{-1}$ sorbitol), LBSG (LB containing $0.5 \mathrm{~mol}$ $\mathrm{L}^{-1}$ sorbitol and $7.5 \%$ GLBY), and NCM. When an $A_{600}$ reading reached $0.9-0.95$, the competent cells were prepared using the conventional electroporation medium (CEM) (0.5 mol L ${ }^{-1}$ sorbitol, 0.5 mol L ${ }^{-1}$ mannitol and $10 \%$ glycer$\mathrm{ol}$ ), and were transformed with $100 \mathrm{ng}$ of pHT3101. As shown in Table 1, transformants appeared only when using unmethylated pHT3101 as exogenous DNA and NCM as growth medium. These results suggest that unmethylated DNA was more acceptable for B-9987 compared with methylated DNA, and the semi-complex NCM medium generates more vegetative B-9987 cells easy to be electropored, which is consistent with the result reported by Zhang et al. [33]. Therefore, unmethylated plasmid DNA and NCM growth medium were used to develop the transformation method for B. marinus B-9987. In addition, cell wall weakening agent glycine was added to the growth medium to interfere peptidoglycan biosynthesis, however, cell lysis occurred even at concentration of as low as $0.5 \%$, and thus decreased transformation efficiency (data not shown).

\subsection{Effects of osmoprotectant on transformation effi- ciency}

Electroporation requires both temporal formation of pores to access DNA and the subsequent resealing of pores $[18,34]$, and thus, the survival rate of electroshocked cells was closely associated with transformation efficiency. To achieve higher survival rate, osmoprotectant glycine betaine (GLYB) was added to the electroporation medium at different concentrations ranging from $2.5 \%$ to $10 \%$. As shown in Figure 2A, the electroporation efficiencies were remarkably enhanced by the addition of GLYB; $7.5 \%$ GLYB gen-

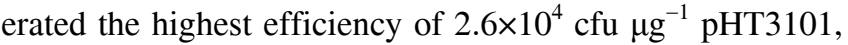
which was increased by nearly $10^{3}$-fold compared with the

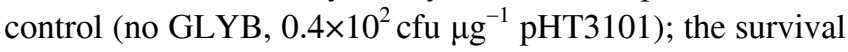
rate of cells electroshocked in electroporation medium without GLYB was only about $12 \%$, while with the addition of GLYB ranging from $2.5 \%$ to $7.5 \%$, the survival rates went up from $38 \%$ to $84 \%$, and the corresponding transformation efficiencies were significantly increased from

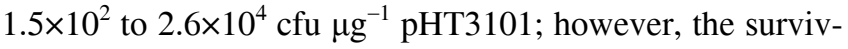
al rate afforded by $10 \%$ GLYB decreased instead, so did the transformation efficiency. Moreover, the electroporation medium supplemented with $7.5 \%$ GLYB was applied to transform cells from the other three growth media with methylated and unmethylated pHT3101, respectively, and all the resulting electroporation efficiencies were significantly improved compared with their corresponding controls (Table 1). These results demonstrated that GLYB is able to offer crucial protection for electroshocked cells and improve their survival rate, and thereby enhance the transformation efficiency of B. marinus B-9987.

\subsection{Effects of HEPES and magnesium ion on trans- formation efficiency}

To further optimize the composition of electroporation medium, buffer salt HEPES and magnesium ion were added to mimic the intracellular $\mathrm{pH}$ and to facilitate the binding of DNA to the surface of cells, respectively. As shown in Table 2 , addition of $1 \mathrm{mmol} \mathrm{L}^{-1}$ HEPES enhanced the transformation efficiency of $B$. marinus $\mathrm{B}-9987$ to $4.1 \times 10^{4}$ cfu $\mu \mathrm{g}^{-1}$ pHT3101; addition of 1 and $2 \mathrm{mmol} \mathrm{L}{ }^{-1} \mathrm{MgCl}_{2}$ also contributed to improvement of transformation efficiency. Moreover, the concentration of $\mathrm{Mg}^{2+}$ was evaluated. The result revealed that $2 \mathrm{mmol} \mathrm{L}{ }^{-1} \mathrm{MgCl}_{2}$ generated the highest transformation efficiency up to $6.0 \times 10^{4} \mathrm{cfu} / \mu \mathrm{g}$ 
pHT3101, while the efficiency declined with further enhancement of $\mathrm{MgCl}_{2}$ concentration (Table 2).

\subsection{Effects of electroporation conditions on transfor- mation efficiency}

Using the optimal growth condition (NCM) and electroporation medium $\left(0.5 \mathrm{~mol} \mathrm{~L}^{-1}\right.$ sorbitol, $0.5 \mathrm{~mol} \mathrm{~L}^{-1}$ mannitol, $10 \%$ glycerol, $7.5 \%$ GLYB, $1 \mathrm{mmol} \mathrm{L}^{-1}$ HEPES, 2 mmol L${ }^{-1} \mathrm{MgCl}_{2}, \mathrm{pH} 7.0$ ) defined in the previous section, the electroporation parameters were optimized with the electric fields ranging from 12 to $24 \mathrm{kV} \mathrm{cm}^{-1}$. Experiments were performed with unmethylated pHT3101. The result showed that the transformation efficiency improved with increase of the electric field from 12 to $20 \mathrm{kV} \mathrm{cm}^{-1}$; the best

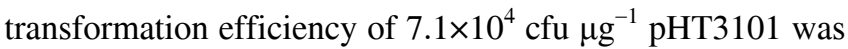
achieved using high electric field of $20 \mathrm{kV} \mathrm{cm}^{-1}$; the transformation efficiency dramatically declined at higher voltages beyond $20 \mathrm{kV} \mathrm{cm}^{-1}$ (Figure 2B).

\subsection{Effects of various plasmids on transformation effi- ciency}

Transformation efficiency is influenced by many factors,

Table 1 Effects of osmoprotectant GLYB on transformation efficiency

\begin{tabular}{|c|c|c|c|c|}
\hline \multirow{3}{*}{ Growth medium ${ }^{\text {a) }}$} & \multicolumn{4}{|c|}{ Transformants/ $\mu$ g plamid DNA pHT3101 } \\
\hline & \multicolumn{2}{|c|}{ No GLYB ${ }^{\mathrm{b})}$} & \multicolumn{2}{|c|}{$7.5 \%$ GLYB } \\
\hline & Methylated DNA & Unmethylated DNA & Methylated DNA & Unmethylated DNA \\
\hline LB & ND & ND & ND & $(0.7 \pm 0.1) \times 10^{3}$ \\
\hline LBS & ND & ND & $(0.2 \pm 0.3) \times 10^{2}$ & $(6.5 \pm 0.5) \times 10^{3}$ \\
\hline LBSG & ND & ND & $(0.2 \pm 0.2) \times 10^{2}$ & $(5.7 \pm 0.3) \times 10^{3}$ \\
\hline $\mathrm{NCM}$ & ND & $(0.4 \pm 0.2) \times 10^{2}$ & $(0.6 \pm 0.3) \times 10^{2}$ & $(2.6 \pm 0.2) \times 10^{4}$ \\
\hline
\end{tabular}

a) LBS, LB containing $0.5 \mathrm{~mol} \mathrm{~L}^{-1}$ sorbitol; LBSG, LB containing $0.5 \mathrm{~mol} \mathrm{~L}{ }^{-1}$ sorbitol and $7.5 \%$ GLYB. b) ND, no transformant detected.
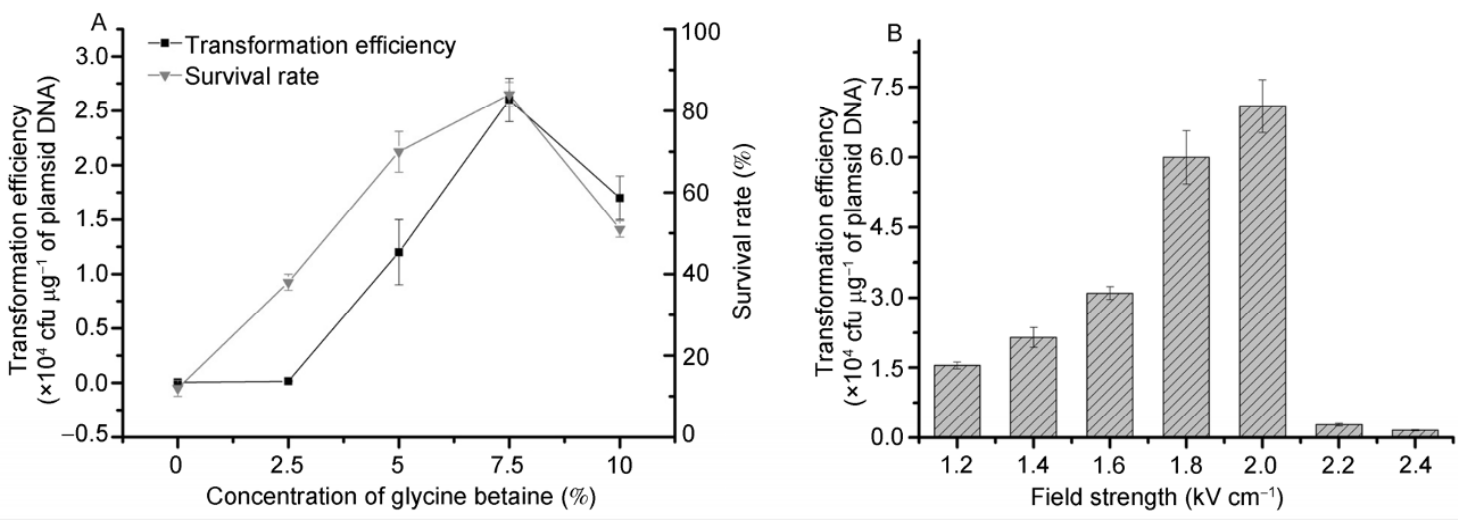

Figure 2 Effects of different factors on transformation efficiency. A, Effects of different concentrations of osmoprotectant GLYB on transformation efficiency and survival rate. The concentrations of GLYB range from 0 to $10 \%$. Error bars represent standard deviation from the mean value between triplicate experiments. $\mathbf{m}$, transformation efficiency; $\boldsymbol{\nabla}$, survival rate. B, Effects of electroporation conditions on transformation efficiency. The electric fields range from 12 to $24 \mathrm{kV} \mathrm{cm}^{-1}$. Error bars represent standard deviation from the mean value between triplicate experiments.

Table 2 Effects of HEPES and magnesium ion on transformation efficiency

\begin{tabular}{|c|c|}
\hline Electroporation medium & Transformants/ $\mu$ g plamid DNA pHT3101 \\
\hline $\mathrm{CEM}^{\mathrm{a})}$ & $(0.4 \pm 0.2) \times 10^{2}$ \\
\hline $\mathrm{CEM}+7.5 \% \mathrm{GLYB}$ & $(2.6 \pm 0.2) \times 10^{4}$ \\
\hline $\mathrm{CEM}+7.5 \% \mathrm{GLYB}+1 \mathrm{mmol} \mathrm{L}{ }^{-1} \mathrm{HEPES}$ & $(4.1 \pm 0.7) \times 10^{4}$ \\
\hline $\mathrm{CEM}+7.5 \% \mathrm{GLYB}+1 \mathrm{mmol} \mathrm{L}-1$ HEPES+1 $\mathrm{mmol} \mathrm{L}^{-1} \mathrm{MgCl}_{2}$ & $(4.5 \pm 0.4) \times 10^{4}$ \\
\hline $\mathrm{CEM}+7.5 \% \mathrm{GLYB}+1 \mathrm{mmol} \mathrm{L}{ }^{-1} \mathrm{HEPES}+2 \mathrm{mmol} \mathrm{L}{ }^{-1} \mathrm{MgCl}_{2}$ & $(6.0 \pm 0.4) \times 10^{4}$ \\
\hline $\mathrm{CEM}+7.5 \% \mathrm{GLYB}+1 \mathrm{mmol} \mathrm{L}{ }^{-1} \mathrm{HEPES}+4 \mathrm{mmol} \mathrm{L}{ }^{-1} \mathrm{MgCl}_{2}$ & $(1.5 \pm 0.2) \times 10^{4}$ \\
\hline $\mathrm{CEM}+7.5 \% \mathrm{GLYB}+1 \mathrm{mmol} \mathrm{L}{ }^{-1} \mathrm{HEPES}+8 \mathrm{mmol} \mathrm{L} \mathrm{MgCl}_{2}$ & $(6.5 \pm 0.2) \times 10^{3}$ \\
\hline $\mathrm{CEM}+7.5 \% \mathrm{GLYB}+1 \mathrm{mmol} \mathrm{L}{ }^{-1} \mathrm{HEPES}+10 \mathrm{mmol} \mathrm{L}{ }^{-1} \mathrm{MgCl}_{2}$ & $(6.0 \pm 0.1) \times 10^{3}$ \\
\hline
\end{tabular}

a) CEM, conventional eletroporation medium. 
especially replication mechanism of the plasmids. pHT3101 harbors the replication region of a resident plasmid of $\mathrm{Ba}$ cillus thuringiensis. To further evaluate the optimized protocol, the other two plasmids carrying divergent replicons and conferring different antibiotic resistance were also tested, including pKSV7 with the temperature-sensitive origin of replication for B. subtilis [23] and pIKM1 with the replication region of $B$. subtilis plasmid pIM13 [24]. As shown in Table 3, the transformation efficiencies for unmethylated pKSV7 and pIKM1 were $4.1 \times 10^{2}$ and $1.0 \times 10^{2} \mathrm{cfu} \mathrm{g}^{-1}$ plasmid DNA, respectively, which were much lower than that of unmethylated pHT3101; conversely, no transformant appeared for methylated pKSV7 and pIKM1, and only a few transformants were obtained for methylated pHT3101. The successful introduction of pKSV7 into $B$. marinus B-9987 allows for performing gene inactivation in this strain.

\subsection{Heterologous expression of GFP in $B$. marinus B-9987}

By using the developed protocol, unmethylated p3101GFP isolated from E. coli ET12567, which harbors a GFP gene under the control of the promoter of glyceraldehyde-3phosphate dehydrogenase gene gapDH (gapDHp), was introduced into B. marinus B-9987 to generate B-9987/gfp. After confirmation by plasmid isolation and restriction digestion, in vivo fluorescence imaging was performed to investigate the expression of GFP. Strong fluorescence emission was detected in B-9987/gfp (Figure 3B), in contrast, no fluorescence was observed in the negative control B-9987/pHT3101 (Figure 3D), demonstrating the expression of GFP in $B$. marinus B-9987. This also suggests that p3101GFP could be used as a reporter plasmid in B. marinus B-9987.

\subsection{Overexpression of the phosphopantetheinyl trans- ferase gene $s f p$ in $B$. marinus B-9987}

The selected $s f p$ gene was overexpressed to demonstrate the application of the established protocol in genetic manipulation of B. marinus B-9987. Unmethylated p3101SFP was introduced into B. marinus B-9987 by the electroporation protocol developed in the study. The resulting transformants
(B-9987/sfp) were confirmed by plasmid isolation and subsequent restriction analysis. Fermentation broths of B-9987/sfp followed by extraction and HPLC analysis showed that overexpression of $s f p$ led to increment of the macrolactin A production to $29 \mathrm{mg} \mathrm{L}^{-1}$ (Figure 4A, panel iii), which is about 1.6-fold as compared to that of the wild type strain $\left(18 \mathrm{mg} \mathrm{L}^{-1}\right)$ (Figure $4 \mathrm{~A}$, panel ii). The identity of macrolactin A was determined by comparison with the standard [5] (Figure 4A, panel i), exhibiting the same retention time and UV spectrum (Figure 4B), and was further confirmed by MS analysis, giving molecular weights of $349.1\left[\mathrm{M}-3 \mathrm{H}_{2} \mathrm{O}+\mathrm{H}\right]^{+}, 367.2\left[\mathrm{M}-2 \mathrm{H}_{2} \mathrm{O}+\mathrm{H}\right]^{+}, 385.2[\mathrm{M}-$ $\left.\mathrm{H}_{2} \mathrm{O}+\mathrm{H}\right]^{+}$and $425.2[\mathrm{M}+\mathrm{Na}]^{+}$, which were consistent with the molecular formula $\mathrm{C}_{24} \mathrm{H}_{34} \mathrm{O}_{5}$ for macrolactin A (Figure 4C). As a result, the biocontrol efficacy of B-9987/sfp could probably be enhanced, indicating this strategy would potentially be applicable to improvement of other biocontrol strains.
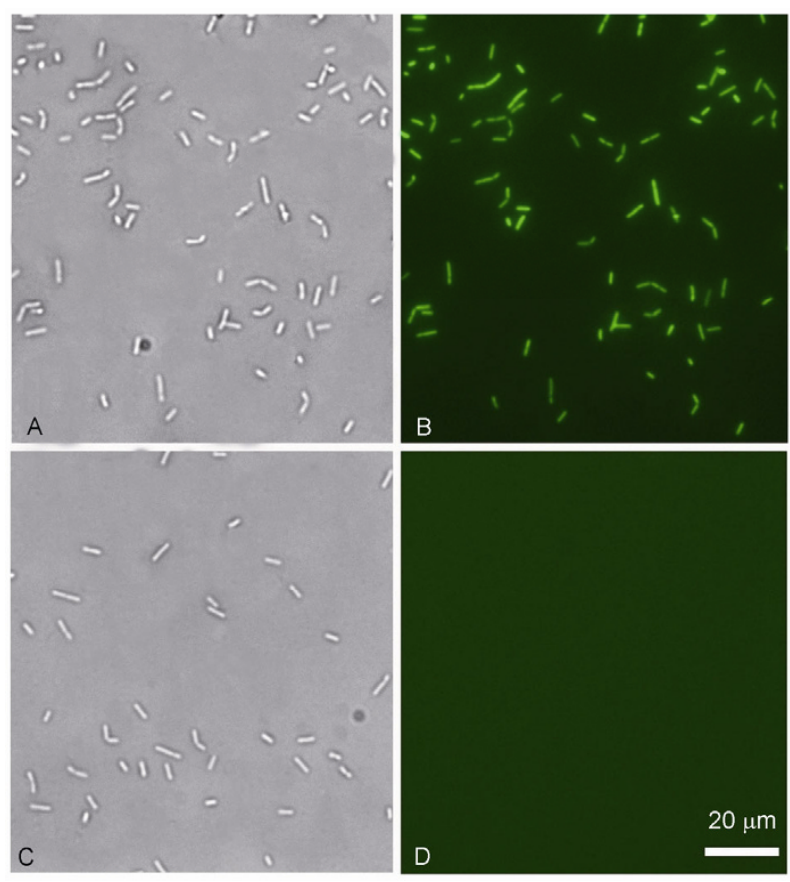

Figure 3 Fluorescent images of B. marinus B-9987/gfp (A and B) and B-9987/pHT3101 (C and D). A and C, Bright field images. B and D, Fluorescence images. Cells were excited at $488 \mathrm{~nm}$.

Table 3 Transformation efficiencies of B. marinus B-9987 with various plasmids

\begin{tabular}{|c|c|c|c|c|c|}
\hline \multirow{2}{*}{ Plasmid } & \multirow{2}{*}{ Size $(\mathrm{kb})$} & \multirow{2}{*}{ Resistance marker ${ }^{\text {a) }}$} & \multirow{2}{*}{ Replicon in Bacillus ${ }^{\text {b) }}$} & \multicolumn{2}{|c|}{ Transformants/ $\mu \mathrm{g}$ plamid DNA } \\
\hline & & & & Methylated DNA ${ }^{\mathrm{c})}$ & Unmethylated DNA \\
\hline pHT3101 & 6.6 & $\operatorname{Erm}^{\mathrm{R}}$ & B. thuringiensis & $(0.8 \pm 0.3) \times 10^{2}$ & $(7.1 \pm 0.3) \times 10^{4}$ \\
\hline pKSV7 & 6.9 & $\mathrm{Cm}^{\mathrm{R}}$ & B. subtilis, ts & ND & $(4.1 \pm 0.5) \times 10^{2}$ \\
\hline pIKM1 & 6.2 & $\mathrm{Kan}^{\mathrm{R}}$ & B. subtilis & ND & $(1.0 \pm 0.6) \times 10^{2}$ \\
\hline
\end{tabular}

a) $\mathrm{Erm}^{\mathrm{R}}$, erythromycin resistance; $\mathrm{Cm}^{\mathrm{R}}$, chloramphenicol resistance; $\mathrm{Kan}^{\mathrm{R}}$, kanamycin resistance. b) ts, temperature sensitive. c) ND, no transformant detected. 

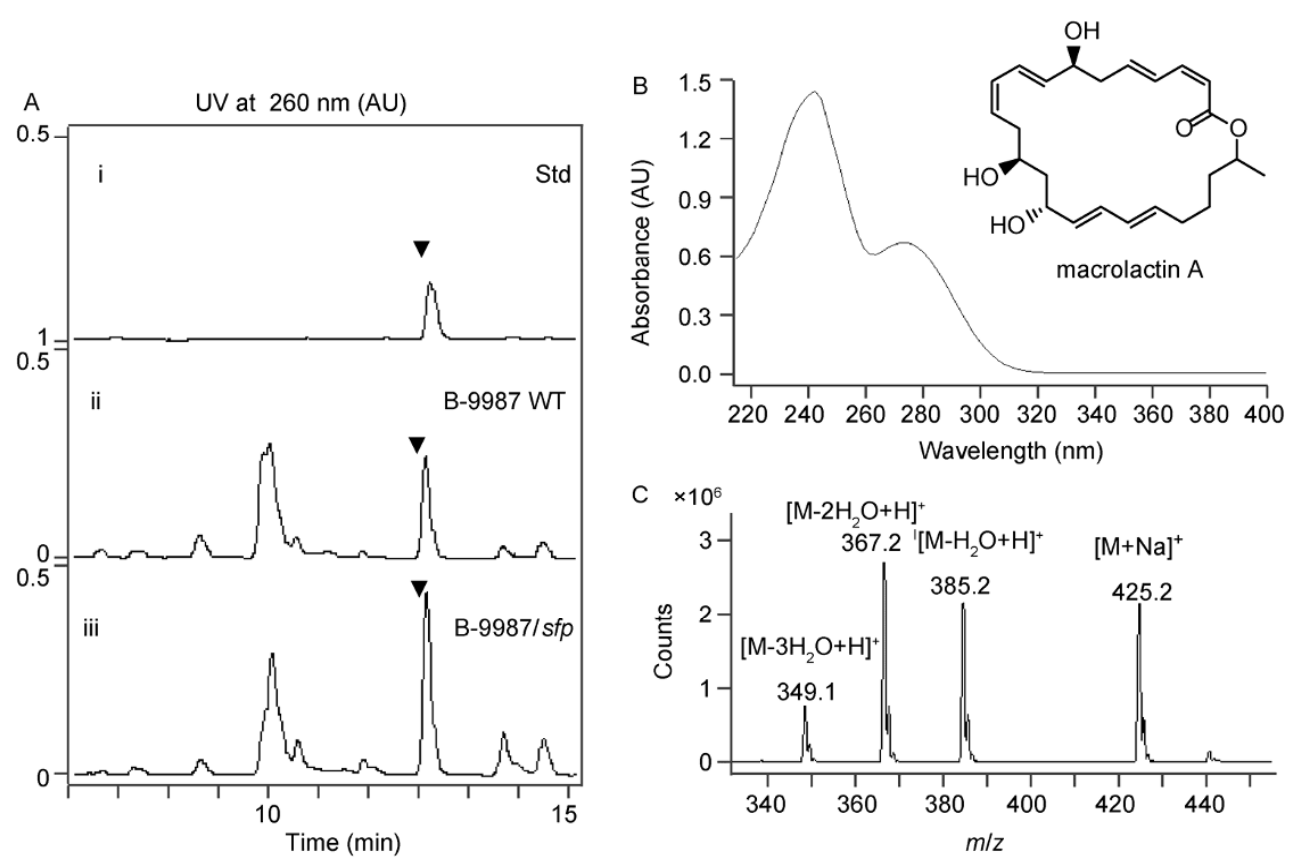

Figure 4 Detection of macrolactin A production. A, HPLC traces of the fermentation broths of B. marinus B-9987 strains. (i) Macrolactin A standard; (ii) wild-type strain B-9987; (iii) overexpression strain B-9987/sfp. $\boldsymbol{\nabla}$, macrolactin A. B, Chemical structure of macrolactin A and its UV spectrum. C, ESI-MS spectrum of macrolactin A.

\subsection{Application of the developed protocol to other ma- rine-derived Bacillus strains}

To detect the applicability of the developed protocol to other marine-derived Bacillus strains, Bacillus licheniforms strain EI-34-6, which was originally isolated from the surface of a marine alga [21], was tested. The B. licheniforms strain EI-34-6 cells were cultured in NCM growth medium, and the competent cells were prepared by using three different electroporation media, including CEM, CEM supplemented with $7.5 \%$ GLYB, and CEM supplemented with 7.5\% GLYB, $1 \mathrm{mmol} \mathrm{L}{ }^{-1}$ HEPES, and $2 \mathrm{mmol} \mathrm{L}^{-1} \mathrm{MgCl}_{2}$. The resulting transformation efficiencies were $6.8 \times 10^{4}$, $4.4 \times 10^{5}$, and $1.1 \times 10^{6} \mathrm{cfu}^{\mathrm{g}} \mathrm{g}^{-1}$ unmethylated pHT3101, respectively, and the optimized electroporation medium developed in this study generated the highest transformation efficiency. These results indicated that the established electroporation protocol is also applicable to the marine-derived B. licheniforms strain EI-34-6.

\section{Discussion}

An efficient transformation system is essential for in vivo studies and further practical applications [35]. It is acknowledged that transformation of environmental Bacillus strains has been very challenging. Many reported transformation protocols are often very species or strain specific, and do not always work for naturally isolated strains, and hence, these strains are often abandoned in favor of amenable strains [17,33]. Field trails proved the marine-derived $B$. marinus B-9987 is an effective biological control agent against fungal plant diseases [6], therefore, it is valuable to understand its biocontrol mechanism on molecular level and further to improve the strain genetically. In the present study, to develop an efficient and robust transform protocol for B. marinus B-9987, major efforts were dedicated to circumvention of restriction barrier, decrease of sporulation rate and improvement of survival rate.

R-M systems are believed to defend bacteria against intrusion of exogenous DNA, and thus significantly decrease transformation efficiency [36]. Many bacterial strains have been found to restrict DNA with Dam and Dcm methylation. For instance, Bacillus anthracis was able to be transformed by DNA from $d a m, d c m$-deficient $E$. coli strain but hardly by DNA from dam-proficient E. coli strain [37,38]; Dcm methylation was reported to be detrimental to plasmid transformation in Clostridium thermocellum [39]. In this study, the transformation efficiency of unmethylated pHT3101 was significantly increased by about 300-1000fold compared to methylated pHT3101 from E. coli DH5 $\alpha$ (Tables 1 and 3), suggesting that B-9987 encodes restriction enzymes against Dam-methylated (containing m5A) or/and Dcm-methylated (containing m5C) DNA.

The Bacillus endospores are characterized by a relatively dehydrated protoplast encased in integument layers, including spore coat, cortex, and primordial cell wall, which endow the spores with resistance to a variety of harsh treatments, such as heat, UV light, desiccation, and toxic chemicals [40]. Endospores could barely be transformed, and thus sporulation rate is one of the crucial factors for transformation. As the morphology differentiation is affected greatly by growth condition [31,41], media with different nutritional ingredients and osmotic agents were tested. Compared with the complex media, the semi-complex me- 
dium NCM afforded more vegetative cells [33], and thereby gave higher transformation efficiency. Addition of osmotic agents into the growth media can keep the cell environment consistent with the high-osmolarity electroporation medium [27], and hence LBS, LBSG and NCM yielded better efficiency than LB, conversely, addition of GLYB into LBS had barely effect on the efficiency compared with LBS (Table 1).

The transformation efficiency is the combined effects of accessibility of DNA into cells and survivability of the electrically damaged cells. Osmoprotectants are able to help the cell cytoplasm to maintain an equivalent osmotic pressure with external environment, and hence could protect cells from the electrical damages during electroporation [27]. By adding sorbitol and mannitol into the electroporation medium, Xue et al. [27] increased the transformation efficiency of $B$. subtilis by an approximately 5000 -fold. Recently, trehalose [15] and GLYB [25] were also tested for their protection on the cells under stress conditions, and generated improved transformation efficiencies of $B$. subtilis by 100 -fold and 700-fold, respectively. In this study, different concentrations of GLYB and their impacts on survival rate were studied. The survival rate curve clearly proved the protection role of GLYB in the electrical field (Figure 2A). Interestingly, 10\% GLYB decreased the survival rate and thereby decreased transformation efficiency for some unknown reason. Furthermore, addition of $1 \mathrm{mmol} \mathrm{L}^{-1}$ HEPES and $2 \mathrm{mmol} \mathrm{L}^{-1} \mathrm{MgCl}_{2}$ led to increased efficiency by additional 2-fold, but $4 \mathrm{mmol} \mathrm{L}^{-1}$ and above $\mathrm{MgCl}_{2}$ decreased efficiency instead (Table 2). We proposed that because DNA is negatively charged at $\mathrm{pH} 7.0$, which is the $\mathrm{pH}$ value of the electroporation medium, low concentration of $\mathrm{Mg}^{2+}$ is probably helpful for DNA binding to the cell surface; however, higher concentration of $\mathrm{Mg}^{2+}$ can shield DNA's charges and even lead to spark during electroshock, and thus decrease transformation efficiency.

In Bacillus, the PPTases gene $s f p$ is essential to polyketides and nonribosomal peptides antibiotics biosynthesis [42]. The genome of Bacillus subtilis 168 contains intact gene clusters for lipopeptides surfactins and fengycins, but its $s f p$ gene is dysfunctional due to a frameshift mutation $[43,44]$, and hence $B$. subtilis 168 is unable to produce these compounds. However, their production could be restored by introduction of a functional sfp gene [43,45]. Overexpression of key enzymes [46] and regulatory activators [47] has been reported to be effective strategies to improve antibiotics production. In this study, the $s f p$ gene was overexpressed in B-9987 under the control of the strong constitutive promoter gapDHp, whose counterpart in Streptomyces has recently been proved to be much stronger than the commonly-used promoter ermE*p [48]. Thus, macrolactins A production was increased by 1.6-fold compared with that of the wild type strain (Figure 4), which potentially enhanced the biocontrol ability of B-9987. This strategy could be used to improve biocontrol ability of other Bacillus strains.

In summary, a reliable transformation protocol was developed for the marine-derived B. marinus B-9987. The protocol is convenient, efficient, and applicable to other marine-derived Bacillus strain as well. The feasibility of genetic manipulation in B. marinus B-9987 was exemplified by heterologous expression of GFP as a sensitive reporter and overexpression of the PPTase gene $s f p$ leading to production increase of macrolactin A, which provided a novel strategy to improve biocontrol ability of Bacillus strains. This work would be a reference for transformation protocol development of other environmental Bacillus strains.

This work was mainly supported by grants from the National Natural Science Foundation of China (31070072, 31171201) and the Program for New Century Excellent Talents in University (NCET-0900717), and partially supported by the National Key Technologies Research and Development Program (2011BAE06B04) as well. We are grateful to BGSC for providing us B. licheniforms strain EI-34-6 (5A37), Prof. Liu Gang (Institute of Microbiology, Chinese Academy of Sciences, China) for providing us pHT3101 and pKSV7, and Prof. Xu Jian (Qingdao Institute of Bioenergy and Bioprocess Technology, Chinese Academy of Sciences, China) for providing us PIKM1 and pHLO15.

1 Mondol MAM, Shin HJ, Islam MT. Diversity of secondary metabolites from marine Bacillus species: chemistry and biological activity. Mar Drugs, 2013, 8: 2846-2872

2 Luo Y, Tian L, Han F, Li Y. Identification of sea bacterium B-9987 and test of its inhibition to some phytopathogens. Nongyao, 2008, 47: 691-693

3 Liu R, Zhang D, Li Y, Tao L, Tian L. A new antifungal cyclic lipopeptide from Bacillus marinus B-9987. Helv Chim Acta, 2010, 93: $2419-2425$

4 Zhang D, Liu R, Li Y, Tao L, Tian L. Two new antifungal cyclic lipopeptides from Bacillus marinus B-9987. Chem Pharm Bull, 2011, 58: $1630-1634$

5 Xue C, Tian L, Xu M, Deng Z, Lin W. A new 24-membered lactone and a new polyene $\delta$-lactone from the marine bacterium Bacillus marinus. J Antibiot, 2008, 61: 668-674

6 Gustafson K, Roman M, Fenical W. The macrolactins, a novel class of antiviral and cytotoxic macrolides from a deep-sea marine bacterium. J Am Chem Soc, 1989, 111: 7519-7524

7 Kim DH, Kim HK, Kim KM, Kim CK, Jeong MH, Ko CY, Moon $\mathrm{KH}$, Kang JS. Antibacterial activities of macrolactin A and 7-O-succinyl macrolactin A from Bacillus polyfermenticus KJS-2 against vancomycin-resistant enterococci and methicillin-resistant Staphylococcus aureus. Arch Pharmacal Res, 2011, 34: 147-152

8 Ji YH, Kim DH, Kang JS, Kim CG, Chung SU, Hwang SW, Kang KR. Anti-inflammatory composition containing macrolactin A and a derivative thereof as active ingredients. US Patent, US 20120071549 A1

9 Ji YH, Kim DH, Kim JA, Kang JS, Chung SU, Hwang SW, Kang KR, Kang YR. Anti-angiogenic composition containing macrolactin compounds. China Patent, CN 103002892 A

10 Schneider K, Chen X, Vater J, Franke P, Nicholson G, Borriss R, Suessmuth RD. Macrolactin is the polyketide biosynthesis product of the pks 2 cluster of Bacillus amyloliquefaciens FZB42. J Nat Prod, 2007, 70: 1417-1423

11 Quadri LEN, Weinreb PH, Lei M, Nakano MM, Zuber P, Walsh CT. Characterization of Sfp, a Bacillus subtilis phosphopantetheinyl transferase for peptidyl carrier protein domains in peptide synthetases. Biochemistry, 1998, 37: 1585-1595

12 Tian L, Li Y, Zheng L, Wei H, Li S, Zhang J, Luo Y. Preparation method and application of Bacillus marinus wettable powder. China Patent, 200710042798

13 Aune TEV, Aachmann FL. Methodologies to increase the transformation efficiencies and the range of bacteria that can be transformed. Appl Microbiol Biotechnol, 2010, 85: 1301-1313

14 Belliveau BH, Trevors JT. Transformation of Bacillus cereus vegetative cells by electroporation. Appl Environ Microbiol, 1989, 55: 
1649-1652

15 Lu Y, Zhang C, Lv F, Bie X, Lu Z. Study on the electrotransformation conditions of improving transformation efficiency for Bacillus subtilis. Lett Appl Microbiol, 2012, 55: 9-14

16 Vojcic L, Despotovic D, Martinez R, Maurer KH, Schwaneberg U. An efficient transformation method for Bacillus subtilis DB104. Appl Microbiol Biotechnol, 2012, 94: 487-493

17 Romero D, Perez-Garcia A, Veening JW, de Vicente A, Kuipers OP. Transformation of undomesticated strains of Bacillus subtilis by protoplast electroporation. J Microbiol Methods, 2006, 66: 556-559

18 Groot MN, Nieboer F, Abee T. Enhanced transformation efficiency of recalcitrant Bacillus cereus and Bacillus weihenstephanensis isolates upon in vitro methylation of plasmid DNA. Appl Environ Microbiol, 2008, 74: 7817-7820

19 Gao C, Xue Y, Ma Y. Protoplast transformation of recalcitrant alkaliphilic Bacillus sp. with methylated plasmid DNA and a developed hard agar regeneration medium. PLoS ONE, 2011, 6: e28148

20 MacNeil DJ, Gewain KM, Ruby CL, Dezeny G, Gibbons PH, MacNeil T. Analysis of Streptomyces avermitilis genes required for avermectin biosynthesis utilizing a novel integration vector. Gene, 1992, 111: 61-68

21 Yan L, Boyd KG, Adams DR, Burgess JG. Biofilm-specific cross-species induction of antimicrobial compounds in Bacilli. Appl Environ Microbiol, 2003, 69: 3719-3727

22 Lereclus D, Arantes O, Chaufaux J, Lecadet MM. Transformation and expression of a cloned $\delta$-endotoxin gene in Bacillus thuringiensis. FEMS Microbiol Lett, 1989, 60: 211-217

23 Yakhnin H, Babitzke P. Gene replacement method for determining conditions in which Bacillus subtilis genes are essential or dispensable for cell viability. Appl Microbiol Biotechnol, 2004, 64: 382-386

24 Mai V, Lorenz WW, Wiegel J. Transformation of Thermoanaerobacterium sp. strain JW/SL-YS485 with plasmid pIKM1 conferring kanamycin resistance. FEMS Microbiol Lett, 1997, 148: 163-167

25 Meddeb-Mouelhi F, Dulcey C, Beauregard M. High transformation efficiency of Bacillus subtilis with integrative DNA using glycine betaine as osmoprotectant. Anal Biochem, 2012, 424: 127-129

26 Ito M, Nagane M. Improvement of the electro-transformation efficiency of facultatively alkaliphilic Bacillus pseudofirmus OF4 by high osmolarity and glycine treatment. Biosci Biotechnol Biochem, 2001, 65: 2773-2775

27 Xue G, Johnson JS, Dalrymple BP. High osmolarity improves the electro-transformation efficiency of the gram-positive bacteria Bacillus subtilis and Bacillus licheniformis. J Microbiol Methods, 1999, 34 183-191

28 Lin L, Song H, Ji Y, He Z, Pu Y, Zhou J, Xu J. Ultrasound-mediated DNA transformation in thermophilic Gram-positive anaerobes. PLoS ONE, 2010, 5: e12582

29 Landy M, Warren GH, Roseman SB, Colio LG. Bacillomycin: an antibiotic from Bacillus subtilis active against pathogenic fungi. Proc Soc Exp Biol Med, 1948, 67: 539-541

30 Zhang G, Wang W, Deng A, Sun Z, Zhang Y, Liang Y, Che Y, Wen T. A mimicking-of-DNA-methylation-patterns pipeline for overcoming the restriction barrier of bacteria. PLoS Genet, 2012, 8: e1002987

31 Hornstra LM, de Vries YP, de Vos WM, Abee T. Influence of sporulation medium composition on transcription of ger operons and the germination response of spores of Bacillus cereus ATCC 14579. Appl Environ Microbiol, 2006, 72: 3746-3749
32 Kim H, Hahn M, Grabowski P, McPherson DC, Otte MM, Wang R, Ferguson CC, Eichenberger P, Driks A. The Bacillus subtilis spore coat protein interaction network. Mol Microbiol, 2006, 59: 487-502

33 Zhang G, Bao P, Zhang Y, Deng A, Chen N, Wen T. Enhancing electro-transformation competency of recalcitrant Bacillus amyloliquefaciens by combining cell-wall weakening and cell-membrane fluidity disturbing. Anal Biochem, 2011, 409: 130-137

34 Riske KA, Dimova R. Electro-deformation and poration of giant vesicles viewed with high temporal resolution. Biophys J, 2005, 88: 1143-1155

35 Liu B, Wang C, Yang H, Tan H. Establishment of a genetic transformation system and its application in Thermoanaerobacter tengcongensis. J Genet Genomics, 2012, 39: 561-570

36 Labrie SJ, Samson JE, Moineau S. Bacteriophage resistance mechanisms. Nat Rev Microbiol, 2010, 8: 317-327

37 Marrero R, Welkos SL. The transformation frequency of plasmids into Bacillus anthracis is affected by adenine methylation. Gene, 1995, 152: 75-78

38 Sitaraman R, Leppla SH. Methylation-dependent DNA restriction in Bacillus anthracis. Gene, 2012, 494: 44-50

39 Guss AM, Olson DG, Caiazza NC, Lynd LR. Dcm methylation is detrimental to plasmid transformation in Clostridium thermocellum. Biotechnol Biofuels, 2012, 5: 30

40 Atrih A, Zoellner P, Allmaier G, Foster SJ. Structural analysis of Bacillus subtilis 168 endospore peptidoglycan and its role during differentiation. J Bacteriol, 1996, 178: 6173-6183

41 Dawes IW, Mandelstam J. Sporulation of Bacillus subtilus in continuous culture. J Bacteriol, 1970, 103: 529-535

42 Hofemeister J, Conrad B, Adler B, Hofemeister B, Feesche J, Kucheryava N, Steinborn G, Franke P, Grammel N, Zwintscher A, Leenders F, Hitzeroth G, Vater J. Genetic analysis of the biosynthesis of non-ribosomal peptide- and polyketide-like antibiotics, iron uptake and biofilm formation by Bacillus subtilis A1/3. Mol Genet Genomics, 2004, 272: 363-378

43 Nakano MM, Corbell N, Besson J, Zuber P. Isolation and characterization of $s f p$ : a gene that functions in the production of the lipopeptide biosurfactant, surfactin, in Bacillus subtilis. Mol Gen Genet, 1992, 232: 313-321

44 Cosmina P, Rodriguez F, de Ferra F, Grandi G, Perego M, Venema G, van Singeren D. Sequence and analysis of the genetic locus responsible for surfactin synthesis in Bacillus subtilis. Mol Microbiol, 1993, 8: $821-831$

45 Lee YK, Kim SB, Park CS, Kim JG, Oh HM, Yoon BD, Kim HS. Chromosomal integration of $s f p$ gene in Bacillus subtilis to enhance bioavailability of hydrophobic liquids. Appl Microbiol Biotechnol, 2005, 67: 789-794

46 Li Y, Ling H, Li W, Tan H. Improvement of nikkomycin production by enhanced copy of $\operatorname{san} U$ and $\operatorname{san} V$ in Streptomyces ansochromogenes and characterization of a novel glutamate mutase encoded by sanU and $\operatorname{sanV}$. Metab Eng, 2005, 7: 165-173

47 Liu G, Tian Y, Yang H, Tan H. A pathway-specific transcriptional regulatory gene for nikkomycin biosynthesis in Streptomyces ansochromogenes that also influences colony development. Mol Microbiol, 2005, 55: 1855-1866

48 Shao Z, Rao G, Li C, Abil Z, Luo Y, Zhao H. Refactoring the silent spectinabilin gene cluster using a plug-and-play scaffold. ACS Synth Biol, 2013, 2: 662-669

Open Access This article is distributed under the terms of the Creative Commons Attribution License which permits any use, distribution, and reproduction in any medium, provided the original author(s) and source are credited.

\section{Supporting Information}

Table S1 Bacteria and plasmids used in this study

The supporting information is available online at life.scichina.com and link.springer.com. The supporting materials are published as submitted, without typesetting or editing. The responsibility for scientific accuracy and content remains entirely with the authors. 